Témoigner Témoigner. Entre histoire et mémoire

Getuigen Revue pluridisciplinaire de la Fondation Auschwitz

$122 \mid 2016$

Révisionisme et négationisme

\title{
Waarom negationisten gevaarlijk blijven
}

Pourquoi les négationnistes restent dangereux

Why negationnists remain dangerous

\section{Aline Sax}

\section{OpenEdition}

\section{Journals}

Édition électronique

URL : https://journals.openedition.org/temoigner/4147

DOI : $10.4000 /$ temoigner.4147

ISSN : 2506-6390

Éditeur :

Éditions du Centre d'études et de documentation Mémoire d'Auschwitz, Éditions Kimé

Édition imprimée

Date de publication : 2 mai 2016

Pagination : 58-66

ISSN : 2031-4183

Référence électronique

Aline Sax, «Waarom negationisten gevaarlijk blijven», Témoigner. Entre histoire et mémoire [Online], 122 |

2016, Online op 30 septembre 2021, geraadpleegd op 04 janvier 2022. URL: http://

journals.openedition.org/temoigner/4147 ; DOl: https://doi.org/10.4000/temoigner.4147 


\section{Waarom negationisten gevaarlijk blijven}

$\rightarrow$ Aline Sax

Geheugen Collectief

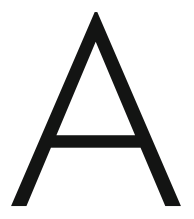

rchiefdocumenten, foto's en filmbeelden, nazibriefwisseling, getuigenissen van slachtoffers én daders en zelfs archeologische sporen en demografische cijfers bewijzen dat het nationaalsocialistische regime in Duitsland tussen 1938 en 1945 systematisch miljoenen Joden en andere 'ongewenste' groepen mensen heeft uitgeroeid. Mensen die dat ontkennen zijn toch ziende blind? Zij spreken duidelijk zonder kennis van zaken en kunnen daardoor door probleemloos genegeerd worden.

Of niet?

Negationisten - mensen die de Holocaust ontkennen - hebben lange tijd relatief ongestoord hun overtuiging kunnen verspreiden. Om die overtuiging geloofwaardigheid te verschaffen, bedienen negationisten zich van een arsenaal aan strategieën om de historische waarheden omtrent de Holocaust aan het wankelen te brengen en hun eigen ideeën plausibel te doen lijken. In dit artikel bekijken we welke strategieën door negationisten ingezet worden en op welke manier dit een gevaar vormt voor de historische wetenschap.

\section{EEN FORUM VOOR NEGATIONISTEN?}

Het ontkennen, minimaliseren, rechtvaardigen of goedkeuren van de genocide die tijdens de Tweede Wereldoorlog door het Duitse nationaalsocialistische regime is gepleegd, is in België strafbaar sinds 23 maart 1995. Ook in heel wat andere (Europese) landen zoals Duitsland, Oostenrijk, Frankrijk, Tsjechië, Hongarije, Nederland, Polen, Portugal, Roemenië, Slovakije, Zwitserland... gelden gelijkaardige wetten (Lechtholz-Zey). Over de zin en de onzin van zo'n wet - die aanleunt bij de antiracismewet maar ook een inperking inhoudt van de vrije meningsuiting - woedt een regelmatig vernieuwd debat. Voorstanders van de wet vinden dat negationisten geen forum mogen krijgen en wijzen op de bijkomende doelstelling van veel negationisten, namelijk het nazisme goedpraten. Tegenstanders wijzen erop dat negationisten door de wet niet van gedachten veranderen maar juist gesterkt worden in hun geloof in een (Joodse) samenzwering. Door de wet zien negationisten zich verplicht ondergronds te gaan waardoor tegenstand veel moeilijker wordt. De wet wordt door tegenstanders ook gezien als een inbreuk op de vrije meningsuiting, die zij belangrijker achten. Ook de vraag of de wet al dan 


\section{REVISIONISME EN NEGATIONISME}

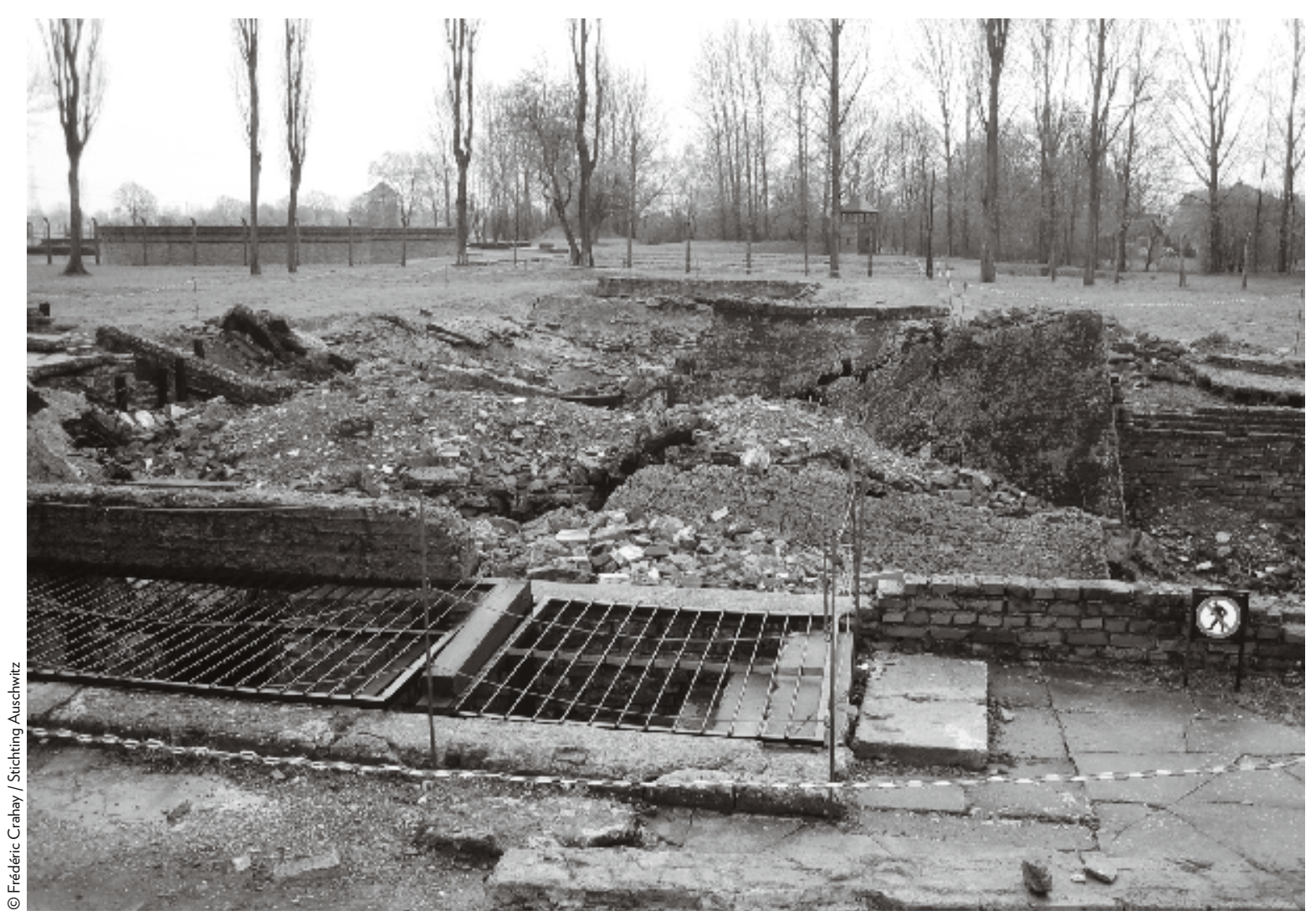

niet uitgebreid moet worden naar alle genociden kent voor- en tegenstanders. ${ }^{1}$ In België leidden die debatten nog niet tot een afschaffing of uitbreiding van de wet. Groot-Brittannië, Denemarken en Zweden hebben al verschillende keren wetsvoorstellen om negationisme strafbaar te maken afgewezen (Bilefski 2007) en ook in de Verenigde Staten bestaat er geen verbod op negationisme. Het first amendment plaatst immers de vrijheid van meningsuiting boven alle andere wetten. Dat zorgt ervoor dat negationisten daar een veel groter forum hebben - en krijgen - dan in Europa. Toch hebben de wetten ook hier relatief lang op zich laten wachten. De eerste negationisten fulmineerden immers al vlak na de oorlog tegen de historische consensus over de Holocaust.

De eerste kiemen van negationistisch ideeëngoed vinden we al ten tijde van de processen van Neurenberg. Die rechtszaken werden door sommigen gezien als het proces van de overwinnaars en daardoor a priori onrechtvaardig (Shermer \& Grobman 2000,40). Een claim die negationisten ook in de decennia erna steeds opnieuw aanhaalden. De eerste invloedrijke negationist was de Franse socialist Paul Rassinier. Tijdens de oorlog was hij als verzetsman zelf gevangene geweest in Buchenwald en Dora. Na de oorlog hoorde hij tegenstrijdige en foutieve getuigenissen - als zouden er gaskamers geweest zijn in Buchenwald. Hij weet dat aan opzettelijke leugens van

_Krematorium II in Birkenau.

(1) Vrielink 2010 en bijdragen in Knack (bv. Decoene, 12 februari 2015) en Joods Actueel (2011), 


\section{DOSSIER}

Waarom negationisten gevaarlijk blijven (vervolg)
_ Gaskamer van

Krematorium III. Fred Leuchter verzamelde er in 1988 (zonder toestemming) brokstukken om ze te bestuderen. de getuigen in plaats van aan verwarring. Vanuit de overtuiging dat de getuigen logen, plaatste hij ook vraagtekens bij de omvang van de genocide. In 1964 publiceerde hij het boek Le Drame des Juifs européens, waarin hij het volgende stelde:

'Wat betreft de gaskamers: de bijna eindeloze processie van valse getuigenissen en vervalste documenten [...] bewijst slechts één ding, namelijk dat de verantwoordelijke autoriteiten van het Derde Rijk op geen enkel moment de intentie hadden om de Joden op welke manier dan ook uit te roeien. Gebeurde deze uitroeiing zonder bevelen? Deze vraagt houdt me al vijftien jaar bezig.' (Widmann 2010)

Zijn verleden als gevangene gaf Rassinier en zijn uitspraken natuurlijk geloofwaardigheid. Vooral vanaf de jaren zestig en zeventig brak het negationisme door met een stroom aan publicaties (Shermer \& Grobman 2000, 40-41). Niet enkel in de Verenigde Staten, maar ook in Europa verspreidden negationisten hun overtuigingen als waarheid.

De bekendste Belgische negationist is Siegfried Verbeke. In de jaren zeventig was hij actief lid van het VMO (Vlaamse Militanten Orde) en drukte hij voor deze

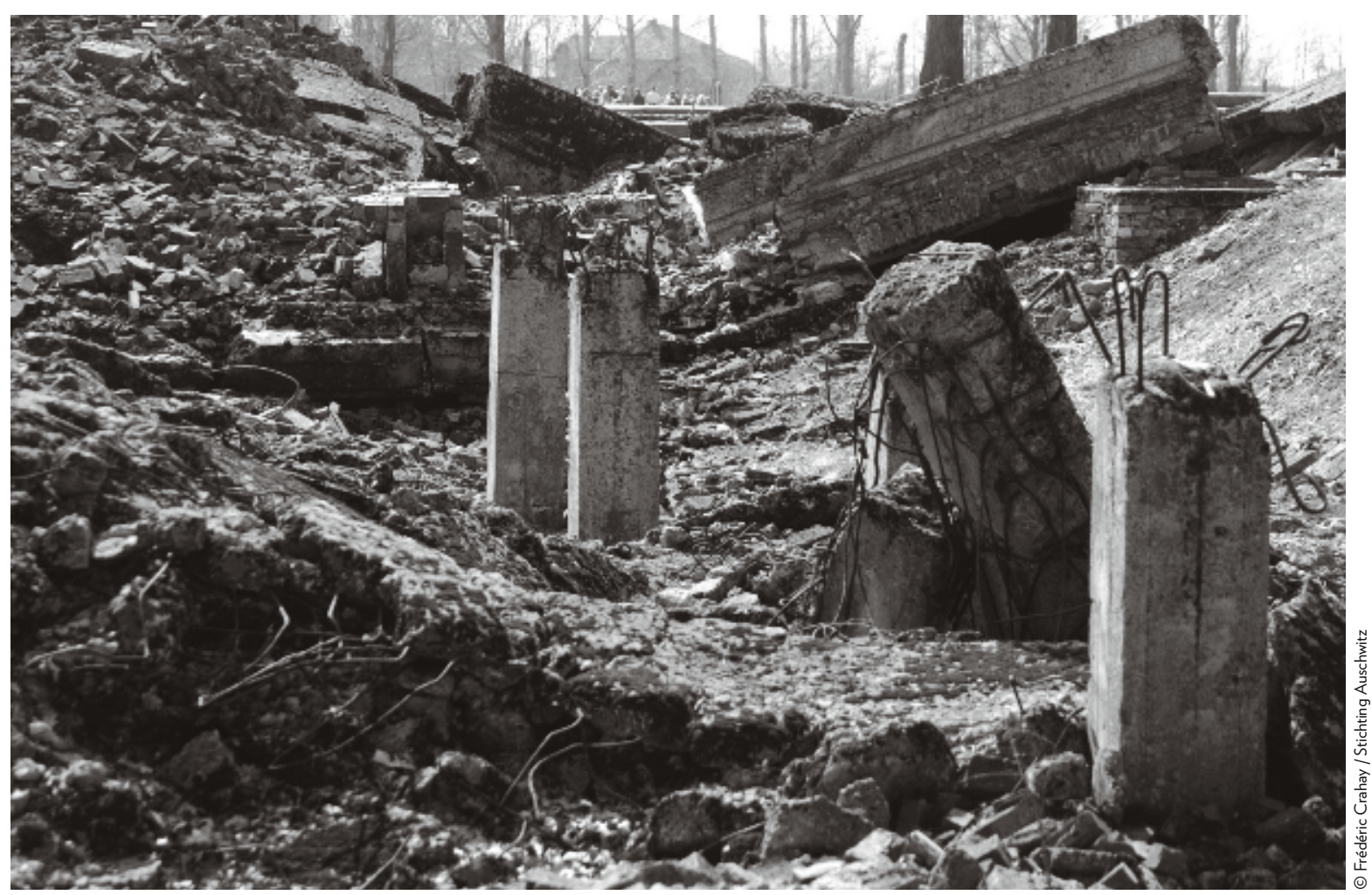


extreem-rechtste privémilitie allerlei neonazistische en antisemitische publicaties. In 1985 richtte hij met zijn broer de vzw Vrij Historisch Onderzoek op, een organisatie die zich toelegde op het verspreiden van negationistische pamfletten en publicaties. Vooral in de jaren negentig liet Vrij Historisch Onderzoek van zich horen. Ze overspoelden scholen, journalisten, politici en historici met hun geschriften. Te pas en te onpas zocht Verbeke de spotlights van de media op om zijn boodschap te verkondigen. Toen in 1995 de wet op het negationisme werd gestemd, was dit koren op de molen van Verbeke, want de wet bewees dat er inderdaad iets te verbergen valt, zo redeneerde hij. De media-aandacht voor de wet, speelde ook in zijn voordeel: een gerechtelijke vervolging zou de vervolgden immers de mogelijkheid geven om hun negationistische standpunten uiteen te zetten en zo verder te verspreiden. 'Wij zullen doorgaan met de genocide, de gaskamers en het hele leugenpaleis te loochenen en te ontmaskeren,' schreef hij in de Nieuwsbrief van het VHO. Dit leverde hem zowel in België als in Nederland en Duitsland enkele veroordelingen op (Brinckman 2005, 4; Timmerman 2005, 4; Vanermen 1996, 126).

Steeds meer worden de pamfletten echter vervangen door een nieuwer en veel makkelijker medium: het internet. Via de website www.vho.org blijft de vereniging haar negationistische ideeëngoed verspreiden bij iedereen die de moeite neemt om eventjes te surfen. Die website wordt gehost op Amerikaanse servers, zodat ze onaantastbaar is voor het Belgische gerecht. Officieel trok Siegfried Verbeke er zijn handen vanaf, maar de naam en het adres van de website blijven rechtstreeks naar zijn vereniging verwijzen.

\section{WAT NEGATIONISTEN BEWEREN}

De standpunten van negationisten kunnen we in grote lijnen samenvatten in een vijftal kerngedachten. Ten eerste bestrijden ze het bestaan van de gaskamers. Ze oordelen dat die ruimtes niet waren bedoeld voor het vermoorden van mensen, maar voor het ontluizen van kleding en bagage. Daarnaast wordt ook het planmatige en systematische karakter van de Jodenuitroeiing ontkend. De Endlösung had niet als doel om de Joden uit te roeien, maar louter om hen te verplaatsen. De kampen waren tijdelijke verblijf- en werkkampen, geen vernietigingskampen om mensen te vermoorden. Dat hangt samen met de betwisting van het getal van zes miljoen doden. Negationisten geven toe dat er Joden gestorven zijn in de kampen, maar dat kwam door erbarmelijke omstandigheden zoals ondervoeding en epidemieën die nu eenmaal door de oorlogsomstandigheden niet te vermijden waren. De Holocaust was daarom niet meer of niet minder ernstig dan de oorlogsmisdaden van de geallieerden, zoals de bombardementen op Dresden en andere Duitse steden. Tot slot keert ook altijd het geloof in een Joodse samenzwering terug. De Holocaust is een Joods verzinsel om Hitler en het nazisme zwart te maken, de staat Israël te legitimeren of de Joden te verrijken. Getuigenissen uit de kampen zijn doelbewuste leugens die binnen die samenzwering gezien moeten worden (Shermer \& Grobman 2000; Lipstadt 1994; Vanermen 1996). 
Waarom negationisten gevaarlijk blijven (vervolg)
(2) Bijvoorbeeld: Pourquoi le Révisionnisme de l'Holocauste? op: http://vho.org/Intro/F/index. html, geraadpleegd 22 oktober 2015.

\section{STRATEGIEËN}

Als we kijken naar het aanwezige bewijs dat de geschiedschrijving over de Holocaust als de systematische uitroeiing van bijna zes miljoen Joden ondersteunt, is het moeilijk te geloven dat negationisten hun visie zouden kunnen doordrukken. Toch slagen zij er keer op keer in om twijfel te zaaien en om mensen aan hun kant te krijgen. Dat heeft minder te maken met wát ze zeggen dan met de manier waarop ze dat doen en de strategieën die ze hanteren om de historiografie over de Holocaust op losse schroeven te zetten.

\section{HET HISTORISCHE METIER UITGESPEELD}

Negationisten proberen de historische wetenschap buitenspel te zetten door de spelregels van die wetenschap overdreven strikt toe te passen. Negationistische publicaties of uitspraken hebben het nooit over negationisme maar over 'revisionisme'. De legitieme vorm van revisionisme betekent dat historici geldende denkbeelden opnieuw onder de loep nemen en aanpassen aan nieuwe bronnen of inzichten. In die vorm maakt revisionisme een belangrijk deel uit van het historische metier. De postmoderne geschiedschrijving gaat er immers van uit dat De Waarheid niet bestaat. Elke beschrijving of analyse van een historische werkelijkheid is een constructie die de historicus maakt op basis van bronnen en een gedegen historische kritiek. Als er andere bronnen of andere inzichten komen, kan die constructie herzien worden. Dat wetenschappelijke debat zorgt voor steeds voortschrijdende inzichten in de historische werkelijkheid zoals die geweest zou kunnen zijn. Ook over de details omtrent de Holocaust zijn niet alle historici het roerend eens. Over het precieze aantal slachtoffers en over het exacte moment waarop de beslissing genomen werd tot uitroeiing bestaat debat.

Negationisten nemen de term 'revisionisme' over om hun bedoelingen te beschrijven. Heel wat negationistische websites of publicaties beginnen dan ook met de geschiedwetenschappelijke uiteenzetting waarom revisionisme nodig is. Een legitieme uiteenzetting die ze evenwel meteen vernauwen tot de 'herziening' van de Holocaust. Negationisten drukken erop dat de ene (lees: hun eigen) visie net zo goed is als de andere (de wetenschappelijk geaccepteerde) visie (Lipstadt 1994, 17-18).

Maar ondanks hun claim is de methode die negationisten in hun argumentatie volgen allerminst een legitieme vorm van revisionisme. Negationisten gaan er immers a priori vanuit dat de Holocaust niet (met voorbedachten rade of in die mate) heeft plaatsgevonden en passen vervolgens de feiten aan die stelling aan. Een legitiem revisionisme betrekt nieuwe bronnen en inzichten in een bestaand debat, zonder evenwel vorige bronnen onder de mat te vegen. Ook over de Holocaust ontstaan op die manier nieuwe, historisch valabele interpretaties. Het negationistische revisionisme doet echter aan selectieve bewijsvoering en kiest enkel die bronnen die de op voorhand vastgelegde conclusies ondersteunen. Op die manier draaien ze de historische methode van onderzoek, analyse en historische kritiek volledig om (McFee). 


\section{NEGATIONISME ALS (PSEUDO)WETENSCHAP}

Negationisten meten zich een pseudowetenschappelijk imago aan om zich als evenwaardig alternatief naast de geschiedwetenschap te kunnen plaatsen. Ze gebruiken daarvoor eigen kanalen en netwerken die de wetenschappelijke gang van zaken imiteren. De grootste vereniging van negationisten in de Verenigde Staten noemt zichzelf het Institute for Historical Review. Het woord Institute moet een wetenschappelijke credibiliteit verlenen en de termen Historical Review doen opzettelijk een breder veld dan enkel de Holocaust vermoeden, wat evenwel niet het geval is. De organisatie heeft bovendien een 'wetenschappelijk' tijdschrift met de erg onschuldig en degelijk klinkende naam Journal of Historical Review. Een naam die niet zou misstaan tussen en soms verwarring oproept met echte historische tijdschriften als The American Historical Review of The Journal of Social History. Ook de Vlaamse vereniging 'Vrij Historisch Onderzoek', opgericht door Siegfried Verbeke, gebruikt een misleidende naam voor een negationistische organisatie. De taal die op die website en in andere negationistische publicaties wordt gehanteerd is eveneens pseudowetenschappelijk; ze lijkt objectief en begint bij feiten en vaststellingen waarmee elk rationeel persoon akkoord kan gaan. Vervolgens neemt de tekst kleine stapjes die telkens meer afwijken van het gangbare geschiedwetenschappelijke discours en eindigen in samenzweringstheorieën, de goedkeuring van het nazistische gedachtegoed en een ontkenning of grove minimalisering van de Jodenuitroeiing. ${ }^{2}$

Het forum waarop negationisten hun ideeën verspreiden, blijft evenwel niet beperkt tot hun eigen kring. In de Verenigde Staten worden negationisten uitgenodigd voor lezingen en gastcolleges en krijgen ze zelfs een forum op de televisie (Lipstadt 1994, 2-4). Maar ook in Frankrijk kwamen in de jaren '70 professoren van de Université de Lyon II en III fel in opspraak vanwege hun negationistische uitspraken en lesinhoud. Het ging hier niet om radicale figuren aan de rand van de maatschappij maar om intellectuelen met academische geloofwaardigheid (Rousso 2006, 67-88). In 1985 behaalde de Franse literatuurwetenschapper Henri Roques een doctoraat aan de universiteit van Nantes met een proefschrift met negationistische inslag (Igounet 2000, 272-276).

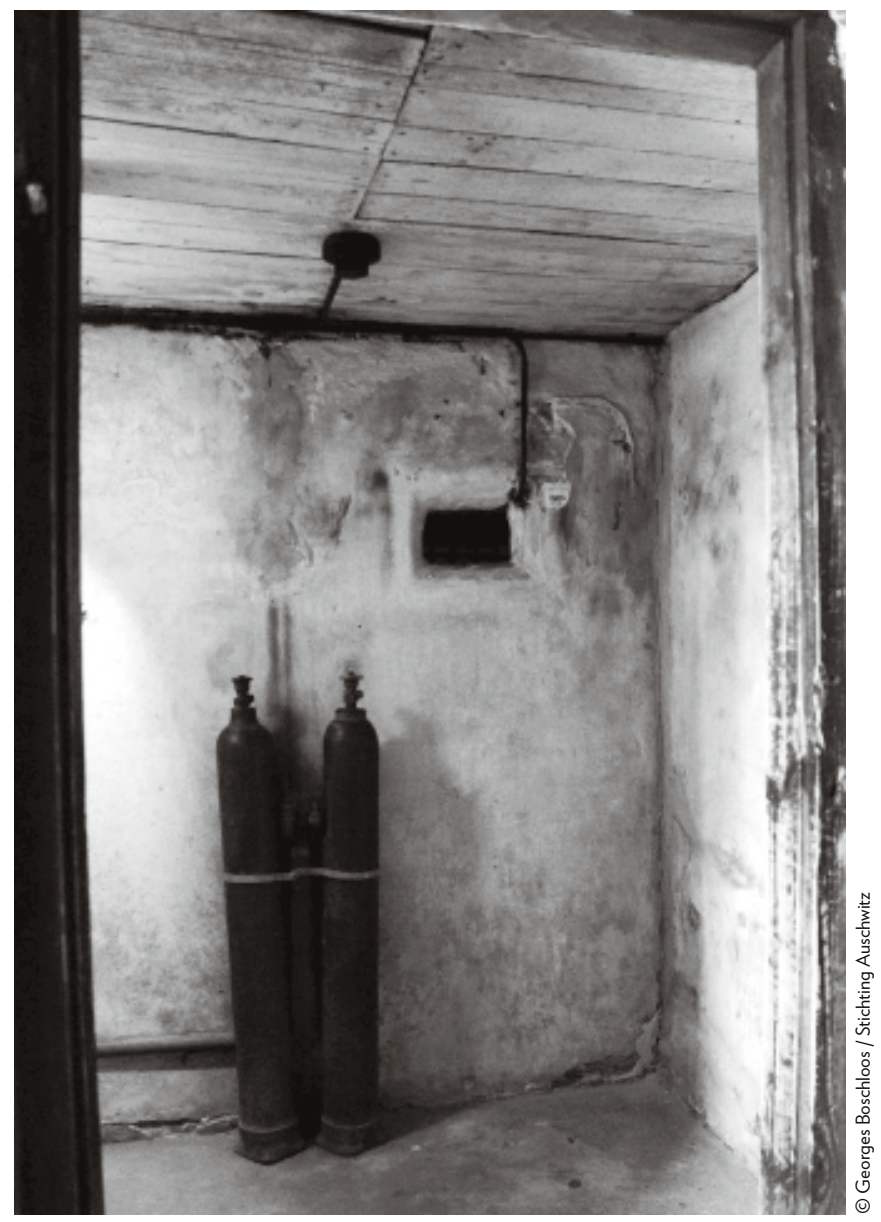

_ Technische ruimte naast de gaskamers in Majdanek. Er werd zowel koolstofmonoxide als Zyklon B gebruikt. 
Waarom negationisten gevaarlijk blijven (vervolg)
‘MYTH BUSTERS’ ZONDER EIGEN ARGUMENTEN

De manier waarop Holocaustontkenners en negationistische teksten argumenteren, lijkt op in eerste instantie aannemelijk, maar daar zit meteen ook de grootste angel. Ze nemen niet de volledige Jodenvervolging op de korrel, maar lichten er slechts enkele elementen uit die ze vervolgens onder vuur nemen. Negationisten hopen dan dat, als ze één element voldoende onderuit halen en over één element voldoende twijfel zaaien, ook het volledige verhaal niet meer geloofwaardig zal zijn. Als je voldoende blijft herhalen en voldoende twijfel kunt zaaien over het bestaan van de gaskamers, is de stap naar de ontkenning van een plan achter de uitroeiing maar klein. Ze volgen de redenering: als één aspect niet waar is, waarom zou het volledige verhaal dan waar zijn, en hopen dat door aan enkele fundamenten te wrikken, het hele beeld als een kaartenhuis in elkaar zakt.

Veel eigen argumenten dragen negationisten meestal niet aan, het gaat hen vooral om het ontkennen en ontkrachten van de argumenten en de bewijzen van de geschiedwetenschap, de getuigen en de bronnen. Als je voldoende twijfel zaait over het standpunt van je tegenstander, hoef je zelf geen standpunt te hebben. Die twijfel zaaien ze onder andere door te wijzen op hun rol als 'myth busters' en complottheorieën te insinueren. Complottheorieën zorgen bij de lezer of toehoorden voor een achterdocht die heel moeilijk te weerleggen is.

\section{VERDACHTE BRONNEN}

De belangrijkste manier waarop negationisten de argumenten van historici proberen onderuit te halen is door de bronnen waarop ze zich baseren verdacht te maken (Vanermen 1996, 23,26,50). Ze nemen een hyperkritische houding aan waarbij ze geloof hechten aan bijna niets dat de historische bronnen zeggen (Rousso 2006, 75). Getuigenissen van slachtoffers worden als Joodse samenzwering en politieke uitbuiting van de Holocaust buitenspel gezet. Er ontstaan soms tegenstrijdigheden of feitelijke onjuistheden in getuigenissen van slachtoffers door verwarring, 'kruisbestuiving' of doordat getuigen niet op de hoogte waren van het precieze reilen en zeilen in de kampen en daardoor zaken gaan aannemen. Negationisten gebruiken die onjuistheden om de volledige getuigenis als onwaarheid te bestempelen en overboord te gooien. Getuigenissen van daders worden dan weer in twijfel getrokken omdat de rechtspraak na de oorlog, waar de meeste van die getuigenissen naar boven kwamen, gevoerd werd door de overwinnaars en dus onmogelijk volledig objectief kon zijn. Ook hier speelden de complottheorieën al een rol. Een voorbeeld van die redenering is de getuigenis van Rudolf Höss, die tussen 1940 en 1943 commandant was van Auschwitz. Op zijn proces getuigde hij gedetailleerd over het vernietigingsproces en de vergassingsprocedure. Negationisten hechten evenwel geen geloof aan deze getuigenis omdat ze ervan uitgaan dat Höss tijdens zijn gevangenschap gefolterd werd door de geallieerden en onder druk is gezet om die getuigenissen te doen. De Fransman Robert Faurisson beweert een bewijs te 
hebben van die folteringen. Hij verwijst naar een gesprek waarbij Höss gezegd zou hebben: 'Ik heb inderdaad ondertekend dat ik 2,5 miljoen Joden heb omgebracht, maar ik zou evengoed ondertekend hebben dat het er 5 miljoen geweest waren.' (Vanermen 1996, 24) Die getuigenis wordt door de negationisten dan weer niet hyperkritisch bekeken.

Een ander voorbeeld van dit hyperkritisch redeneren is dat negationisten de context van de bronnen volledig buiten beschouwing laten. Alleen de bron zelf telt, volgens negationisten. Bronnen worden volledig geïsoleerd, tot op het bot onderzocht totdat ze elke betekenis verliezen. Verbanden tussen verschillende bronnen en de algemene context laten ze daarbij volledig buiten beschouwing. Het dagboek van Anne Frank belandde ook op de onderzoekstafel van de negationist Robert Faurisson. Hij beweerde dat het dagboek vals moet zijn omdat hij, na 'grondig literatuurkritisch onderzoek', vaststelde dat verschillende handschriften en stijlen aan bod kwamen en dat in verschillende uitgaven passages ontbraken of waren toegevoegd. Dat die verschillende stijlen te wijten waren aan het feit dat Anne zelf stukken herschreef omdat ze hoopte die na de oorlog te kunnen publiceren en dat de passages die in de eerste uitgaven ontbraken stukken waren die haar vader te intiem vond om te publiceren (maar later toch weer werden toegevoegd), is contextanalyse en valt dus buiten het 'onderzoek' van Faurisson (Vanermen 1996, 52-57).

Daarnaast proberen negationisten historici ook te ondermijnen met bronnen van positief-wetenschappelijke aard. In 1988 werd een 'wetenschappelijke' studie uitgevoerd waarbij Fred Lechter, een Amerikaans ingenieur die executie-installaties ontwierp, ook de gaskamers in Auschwitz en Majdanek onderzocht. Voor dat onderzoek nam hij cementstalen van de gaskamers die hij onderzocht op giftige stoffen. Hij concludeerde dat er meer sporen van cyanide en Zyklon B aangetroffen zouden zijn in de ontluizingskamers dan in de gaskamers en dat er daardoor geen mensen vergast zouden kunnen zijn in de gaskamers. De Britse historicus en Holocaustontkenner David Irving was naar eigen zeggen hierdoor overtuigd dat de geschiedenis zich veel meer moest richten op exact-wetenschappelijke onderzoeksmethoden en minder op traditionele historische bronnen die 'voor interpretatie vatbaar zijn' (Vanermen 1996, 48 en Eatwell 1991). In 1993 werd een gelijksoortig rapport opgesteld dat met dezelfde methode dezelfde conclusies trekt (Vanermen 1996, 49).

\section{BESLUIT}

Door die pseudowetenschappelijke aanpak waarbij negationisten hun mening als ten minste evenwaardig beschouwen als de wetenschappelijke geschiedschrijving, slagen zij erin twijfel te zaaien over zowel de omvang als de planmatigheid van de Jodenuitroeiing. Hoewel in België openbare revisionistische uitlatingen zeldzaam zijn en meestal vervolgd worden, biedt het internet een schier onuitputtelijke bron van revisionistische websites en teksten. Ondanks de wetgeving kom je ook in België gemakkelijk aan revisionistische geschriften (ze kunnen bijvoorbeeld vrij besteld worden op Amazon). De claim van wetenschappelijkheid maakt deze vrij toegan- 
Waarom negationisten gevaarlijk blijven (vervolg) kelijke teksten veel gevaarlijker dan provocatieve uitspraken of discussies in het openbaar. Enerzijds vormt dat een gevaar voor de objectieve geschiedschrijving, anderzijds is er ook een ethisch gevaar. Als de twijfel die gezaaid wordt over de Holocaust sterk genoeg wordt, zet dat immers de deur open om het nazisme en (neo) nazistisch ideeëngoed goed te praten en salonfähig te maken. I

\section{BIBLIOGRAFIE}

- Dan Bilefsky, 'EU adopts measure outlawing Holocaust denial', The New York Times, 19 april 2007.

- Bart Brinckman, 'Vlaamse peetvader moet naar Duitse cel', De Standaard, 29 oktober 2005, 4.

- Roger Eatwell, 'The Holocaust Denial: A Study in Propaganda Technique', in L. Cheles (red.) Neo-Fascism in Europe, Longman: New York, 1991, 120-146.

- Valérie lgounet, Histoire du négationnisme en France, Parijs: Seuil, 2000.

- Jacqueline Lechtholz-Zey, Laws Banning Holocaust Denial, http://www.genocidepreventionnow.org (geraadpleegd 21 oktober 2015).

- Deborah Lipstadt, Denying the Holocaust, the growing assault on thruth and memory, Londen: Penguin, 1994.

- Gordon McFee, 'Why “Revisionism” Isn't', The Holocaust History Project, http://www.holocaust-history.org/ revisionism-isnt/ (geraadpleegd 12 oktober 2015).

- Georges Timmerman, 'De lange carrière van Siegfried Verbeke', De Morgen, 15 april 2005, 4.

- Henry Rousso, 'The Political and Cultural Roots of Negationism in France', South Central Review 23(1), Fascism, Nazism: Cultural Legacies of Reaction, 2006, 67-88.

- s.n. Pourquoi le Révisionnisme de Holocauste?, http://vho.org//ntro/F/index (geraadpleegd 22 oktober 2015).

- Michael Shermer \& Alex Grobman, Denying history, who says the Holocaust never happened and why do they say it?, Berkeley: University of California Press, 2000.

- Stijn Vanermen, De ontkenning van de Jodenuitroeiing, Brussel: VUB Press, 1996.

- Jochum Vrielink, Van haat gesproken? Een rechtsantropologisch onderzoek naar de bestrijding van rasgerelateerde uitingsdelicten in België, Antwerpen: Maklu, 2010.

- Richard Widmann, Profiles in history: Paul Rassinier, op: Inconvenient History, 2010, http://www.inconvenienthistory.com (geraadpleegd 23 oktober 2015). 